\title{
Changes in geographic clustering of post-traumatic stress disorder and post-traumatic growth seven years after an earthquake in Cauquenes, Chile
}

\author{
Marcelo Leiva-Bianchi, ${ }^{1}$ Carlos Mena, ${ }^{2}$ Yony Ormazábal, ${ }^{2}$ Carlos Serrano, ${ }^{1}$ Pedro $\operatorname{Rojas}^{1}$ \\ ${ }^{1}$ Faculty of Psychology, Laboratory of Methodology for Behaviour and Neurosciences, University of Talca; \\ ${ }^{2}$ Faculty of Forestry Sciences, Geomatics Center, University of Talca, Talca, Chile
}

\begin{abstract}
Recent findings indicate that both disruptive Post-Traumatic Stress Disorder (PTSD) and healthy Post-Traumatic Growth (PTG) responses have some spatial distribution depending on where they are measured and the different degrees of exposure that people may have to a critical event (e.g., earthquake). Less is known about how these responses change as a function of space and time after these events. The objective of this study was to enter deeper into this relationship analysing how PTSD and PTG responses vary in their spatial distribution 6 and 7 years after an earthquake (such as the one that occurred on 27 February, 2010 in Cauquenes City, Chile). Spatial analyses based on Geographic Information Systems (GIS) were performed to detect global and local geographic clustering. Investigating 171 (2016) and 106 (2017) randomly selected adults from Cauquenes, we demonstrated that 7 years after the event only 4 variables were spatially clustered, i.e. personal mental strength, interpersonal relations, new possibilities and appreciation of life), all of them PTG dimensions; This result contrasted with the situation the previous year (2016), when 7 variables were clustered (total PTG, spiritual change, new
\end{abstract}

Correspondence: Yony Ormazábal, Faculty of Forestry Sciences, Geomatics Center, University of Talca, Talca, Chile.

E-mail: yormazabal@utalca.cl

Tel.: +56.71.2201654.

Key words: Post-traumatic stress disorder; post-traumatic growth; earthquake; Geographic Information Systems; Moran's I; Getis-Ord Gi*; Chile.

Funding: This work was supported by the FONDECYT-Chile 1190578 and CONICYT Doctorado en Ciencias Humanas 21181845.

Conflict of interests: The authors declare no potential conflict of interests.

Received for publication: 7 April 2020.

Accepted for publication: 6 September 2020.

(C) Copyright: the Author(s), 2020

Licensee PAGEPress, Italy

Geospatial Health 2020; 15:886

doi:10.4081/gh.2020.886

This article is distributed under the terms of the Creative Commons Attribution Noncommercial License (CC BY-NC 4.0) which permits any noncommercial use, distribution, and reproduction in any medium, provided the original author(s) and source are credited. possibilities, appreciation of life, PTSD symptoms, PTSD reactions and PTSD in total). The spatial identifications found could facilitate the comparison of mental health conditions in populations and the impact of recovery programmes in communities exposed to disasters.

\section{Introduction}

During the course of life, people can be exposed to critical events, such as natural disasters, illness, unemployment, even the death of a loved one. Such events test adaptive capacity and can alter people's mental health both for the short and the long term (IASC, 2007). Not all people face these events equally, nor is their resilience the same. For example, an earthquake can elicit disruptive responses, e.g., Post-Traumatic Stress Disorder (PTSD), anxiety, depression, substance abuse and suicidal ideation, although healthy responses, such as Post-Traumatic Growth (PTG), social support and resilience are also likely to emerge (Bonanno et al., 2005). These authors (2010) and Cairo et al. (2010) indicate that disasters produce at most $30 \%$ of disruptive responses. Variables of exposure-protection to the event, such as social support, being farther from the epicentre or having fewer material losses (LeivaBianchi et al., 2017), are related to greater psychological wellbeing and the emergence of healthier responses, such as engagement in interpersonal contacts, beliefs about mutual helpfulness and benevolence (Kaniasty, 2012).

In this sense, healthy responses of the PTG type are directly related to PTSDs. This dependency is presented as an illusion of impact control in the face of a difficult event (Hobfoll et al., 2007). Likewise, from the perspective of psychosocial impact, healthy responses are considered to correspond to the absence of disruptive responses and the appearance of adaptive responses (Leiva-Bianchi et al., 2017). This adaptation can be successful if the strategy is appropriate for the stressful event to which the individual is exposed (Bonanno et al., 2004; Cheng, 2001). Furthermore, both the absence or presence of these responses and the exposure-protection before the event can be organized into continuums of healthy-disruptive and exposure-protection responses, respectively. Four types of impact combine them: resilience (to respond in a healthy manner when exposed to a particular event), trauma (to respond disruptively when exposed), safety, i.e. to be a bystander (to respond in healthy manner when protected) and paradoxical (to respond disruptively when protected from the event) as proposed by Leiva-Bianchi et al. (2019).

Impacts can have different trajectories over time (Bonanno, 2004), which makes the prevalence of disruptive or healthy responses vary according to when they are measured (Bonanno et al., 2010; 
Milliken et al., 2007). Recently, it has been discovered that both disruptive and healthy responses have a special distribution that depends on where they occur and the different degrees of exposure that people may have before a shocking event (Leiva-Bianchi et al., 2019). Likewise, people may be exposed to more than one event of a similar nature at different times, in these exposure time periods, both healthy and disruptive responses can coexist in the same person (Morland et al., 2008; Morgan et al., 2011; Leiva-Bianchi et al., 2017). Natural disasters occur frequently in Chile (e.g., earthquakes and tsunamis in 2010, forest fires in 2017 and droughts in 20122019) and when their size and severity are considerable with large number of people affected, disaster areas are decreed by the government (Diario Oficial de la República de Chile, 2010; 2017; 2019). The objective of this study is to enter more deeply into the interaction between space and time that the disruptive or healthy responses have after a critical event such as a natural disaster. For this, the frequency and spatial distribution of PTSD and PTG responses are compared, six and seven years after the earthquake of 27 February, 2010 (27F) in the urban nucleus of Cauquenes in Chile.

\section{Materials and methods}

\section{Study site and impact}

The study was conducted in the urban centre of Cauquenes,
Maule Region, Chile (Figure 1). The city is made up of the following sectors and villages: the city centre (downtown) which concentrates the commercial activities in combination with the oldest residential sectors; in the Northwest, the "Los Poetas" and "Bombero Venegas" suburbs, which are working-class residential sectors with medium urban development; in the Northeast, the "Fernández" suburb is a residential sector with high poverty rates and poor urban development; and in the South, the "Estación" suburb that is a residential sector characterized by the higher income and greater urban development.

The registered effects of the $27 \mathrm{~F}$ earthquake in the county according to the post-earthquake survey of the Ministry of Planning (Ministerio de Planificación, MIDEPLAN, 2010) indicate that $25.1 \%$ of the population experienced no damage, $41.3 \%$ minor damage, $16.2 \%$ major damage and $17.4 \%$ saw a total loss of their dwellings. By 2016, data collected for this study indicate that $24.6 \%$ of the population experienced no damage, $32.2 \%$ minor damage, $19.9 \%$ major damage and $23.4 \%$ lost all of their dwellings. For its part, in 2017, it was registered that $7.5 \%$ experienced no damage, $17 \%$ minor damage, $30.2 \%$ major damage and $45.3 \%$ saw a total loss of their dwellings.

\section{Participants}

From a total of 13,695 dwellings distributed over 466 blocks in the urban area of the Cauquenes borough (INE, 2019a), a sub-sample or two-stage sample was built (the first stage was the urban blocks and within these the dwellings). The participation of a suit-

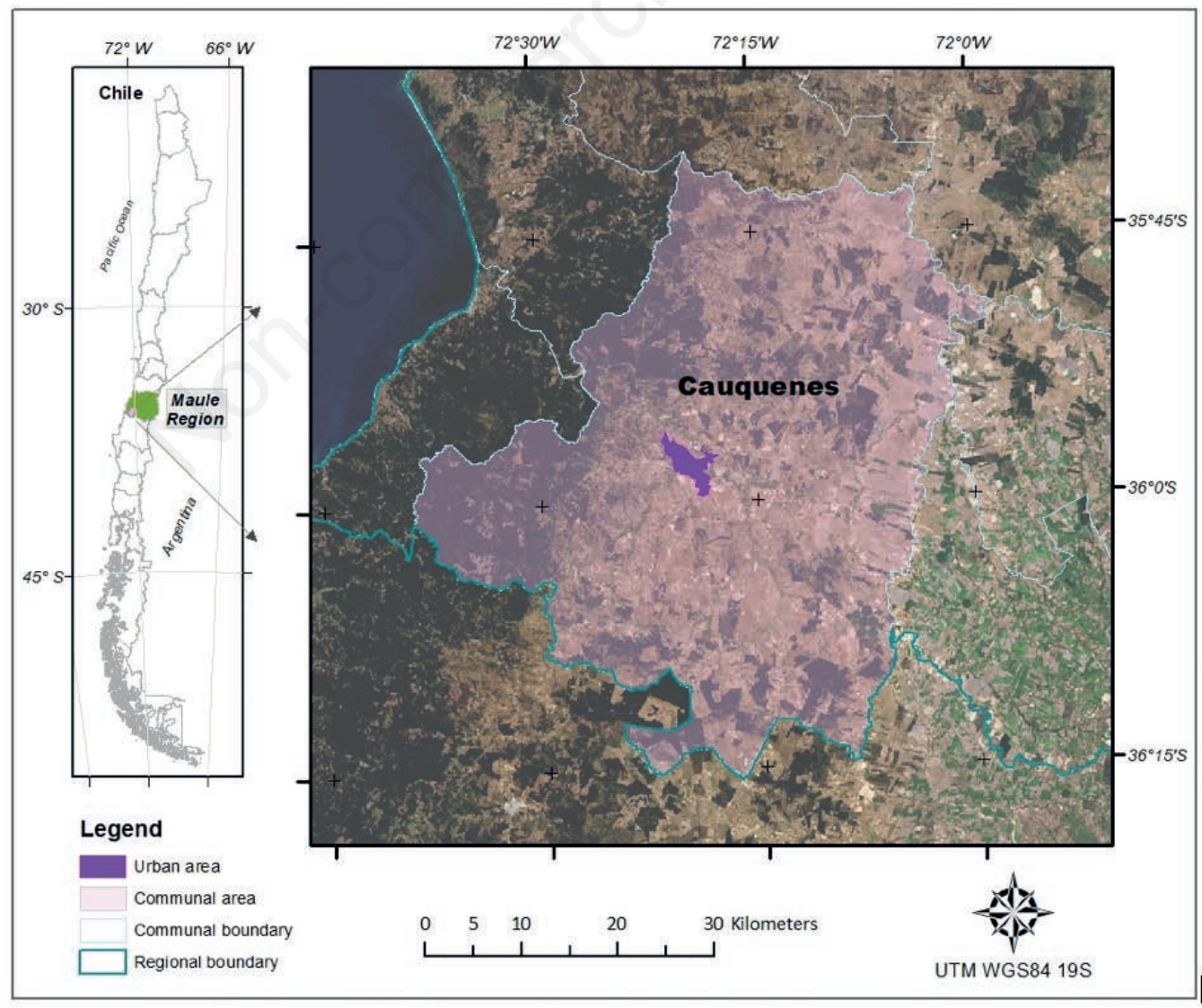

Figure 1. Localisation of the study area. 
able informant was required for each dwelling, e.g., a person over 18 and head of the household. The data were collected longitudinally (same house and same person) during the months of July and September of 2016 and 2017. The estimates were subject to a maximum error of $7.5 \%$, a confidence level of $95 \%$, a power of $80 \%$ and a maximum variance of $50 \%$. In 2016,171 people $(65.5 \%$ women) participated and in 2017 , a total of 106 people $(70.8 \%$ women) (Table 1). The age group with the highest frequency was the $>65$ years age-group $(33.3 \%)$ in 2016 and the same $(36.8 \%)$ in 2017. Although $38 \%$ of the original sample was lost in the survey application in 2017, this percentage is within what is acceptable as indicated by the National Institute of Statistics (Instituto Nacional de Estadística, INE, 2019b). On the other hand, the intercensal growth rate between 2002 and 2017 was $-0.12 \%$, indicating only a small decline in the population size (INE, 2020). Therefore, the 2016 and 2017 samples were equally representative, with only a marginal number of people leaving the area after the $27 \mathrm{~F}$ earthquake.

\section{Assessment of severity of symptoms}

The Short Post-Traumatic Stress Disorder Rating Interview (SPRINT-E) and Post-traumatic Growth Inventory (PTGI) were applied after voluntarily agreeing to participate. SPRINT-E is a scale with 3 items that measures PTSD symptoms (e.g., re-experimentation; avoidance; hyper-arousal) and 9 items that measure other reactions expected after a disaster (e.g., adjustment to daily life; alcohol use; drug use; suicidal inclination). Each symptom or reaction has a scale ranging from 0 up to 4 , which means a possible maximum of 48 points. A total of 9 points or more, including 3 measures with at least 3 points, is considered a case of PTSD (Norris et al., 2008; Leiva-Bianchi and Gallardo, 2013). PTGI, on the other hand, is composed of 21 measures that gauge the mental growth and personal development of those having experienced a critical event such as a disaster (e.g., relating to others; new possibilities; personal mental strength; spiritual change; and appreciation of life). Each item is evaluated with a scale from 0 up to 5 (105 points maximum). The growth can vary from little change ( 0 to 50 points); moderate change (51-74 points); or major change (>75 points) (Tedeschi and Calhoun, 1996; Leiva-Bianchi and Araneda, 2015).

\section{The post-traumatic effects geodata base}

The study referred to a georeferenced database containing all the relevant geo-information for Cauquenes (streets and urban blocks obtained from Military Geographic Institute of Chile). The cartography and satellite images from the Worldview satellites (https://www.maxar.com) were built in ArcGIS software v. 10 (ESRI, Redlands, CA, USA). All information about post-traumatic effects collected by survey was georeferenced into the database using the residential address recorded during the psychological evaluation of every single individual. Thus, two Geographic Information Systems (GIS) collections (one for each study year) were created using georeferenced points as representative elements for individuals linking all psychological evaluation data in a thematic table (Mena et al., 2017). These GIS datasets were later used as the main input data for the calculation of post-traumatic rates and the spatial autocorrelation analyses.

\section{Global and local spatial association analyses}

Moran's I statistic was calculated according to Zhao et al. (2013) and Chen et al. (2015) in order to identify the variables under study that present a global clustering. The index values can range between -1 to +1 , where a value near +1 indicates that the variable tends to cluster, meaning that values registered for participants at one location are similar between neighbours; and a value near -1 indicates that higher and lower measurement values are heterogeneously distributed in the analysed area. The threshold distance used in the analyses for the searching ratio was $700 \mathrm{~m}$, a distance that represent a mean size of a suburb-sector of the city.

The Gi* local statistic (Ord and Getis, 1995) was used to analyse the spatial correlation among post-traumatic indices of neighbouring participants in order to detect statistically significant spatial clusters of high value (hotspots) or the opposite (coldspots). This analysis was completed only for those psychological variables that showed a global clustered condition (determined by Moran's I statistic). As the Gi* statistic itself is a $z$-score, no further calculations were needed so the $z$-score and the $p$-value were used to identify where individuals with either high or low values were clustered spatially. Participants with a positive $z$-score thus corresponded to a spatial clustering of high values and those with a negative z-score correspond to one with low ones. The results can be portrayed on a map where higher (or lower) $z$-score values indicate places of more intense clustering, while $z$-scores close to zero do not indicate any apparent clustering (Getis and Aldstadt, 2004).

\section{Results}

In 2016, the prevalence of PTSD associated with the impact of the $27 \mathrm{~F}$ earthquake was $24.6 \%(76.2 \%$ women $)$, while the percentage of people with high PTG was 55\% (69.1\% women). By contrast, in 2017 these rates of prevalence were $46.2 \%(63.3 \%$ women) and $76.4 \%$ (75.3\% women), respectively.

The results of the Moran's $I$ statistic are shown in Table 2 for the years 2016 and 2017. As can be seen, the 7 variables under analysis in 2016 were spatially clustered, while only 4 of them were clustered in 2017. In turn, Table 3 shows the mean values for hotspots and coldspots of clustered variables detected by application of the local Gi* statistic for the two years. For the most interesting variables, maps were elaborated in order to visualize geographically the spots detected in the city context (Figure 2).

Table 1. The study population surveyed in 2016 and 2017.

\begin{tabular}{lcccc} 
& \multicolumn{2}{c}{2016} & \multicolumn{2}{c}{2017} \\
Variable & N & $\%$ & N & $\%$ \\
Women & 112 & 65.5 & 75 & 70.8 \\
Men & 59 & 34.5 & 31 & 29.2 \\
\hline Age $>65$ & 57 & 33.3 & 39 & 36.8 \\
High school completed & 52 & 30.4 & 29 & 27.4 \\
\hline Living alone & 20 & 11.7 & 20 & 18.9 \\
Income level: 281-563 USD* & 78 & 45.6 & 53 & 50.0 \\
\hline * United States dollars. & & & &
\end{tabular}




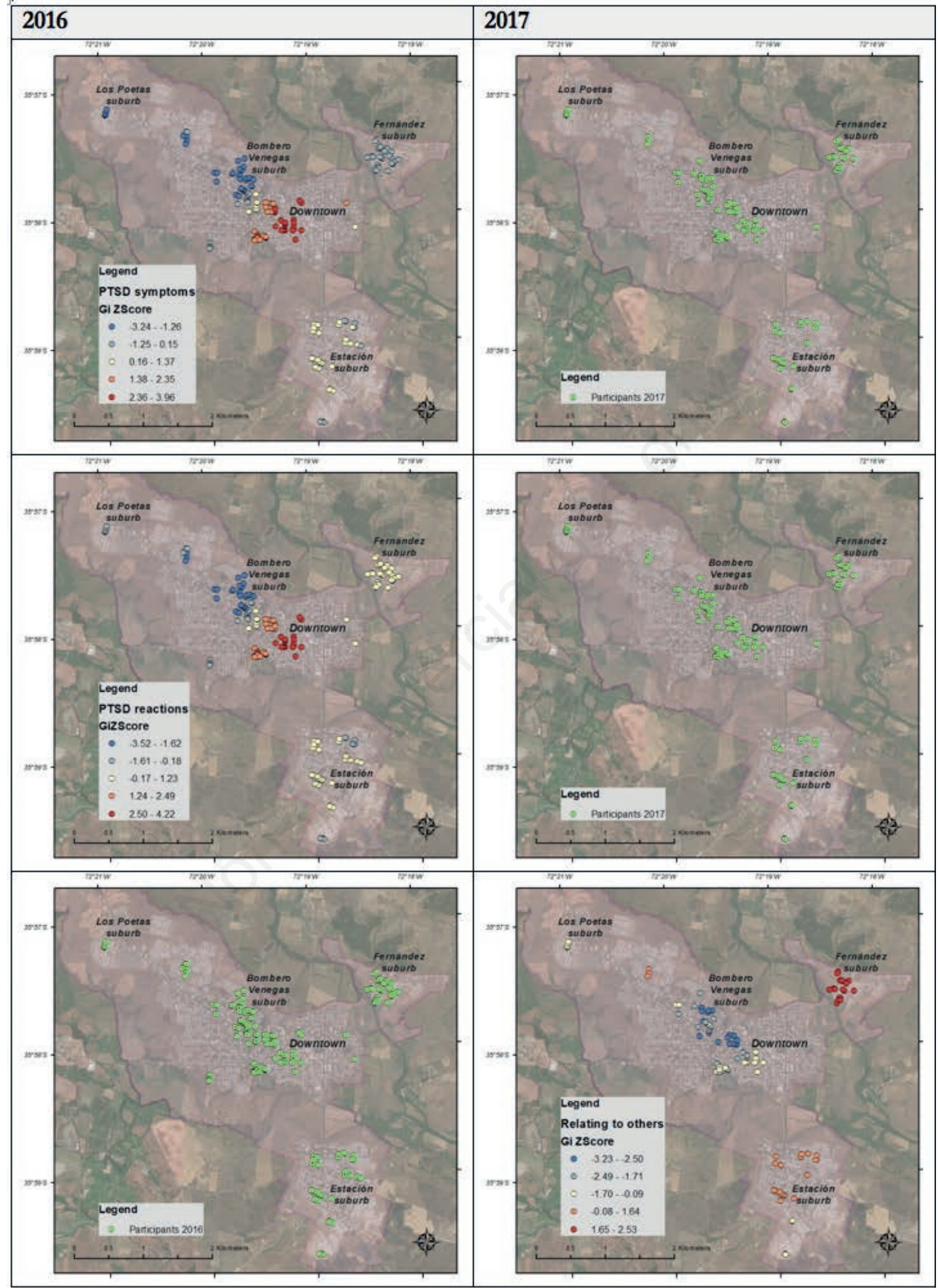

Figure 2. Getis-Ord Gi* statistic for clustered disruptive (PTSD) and health (PTG). Continued on the next page. 


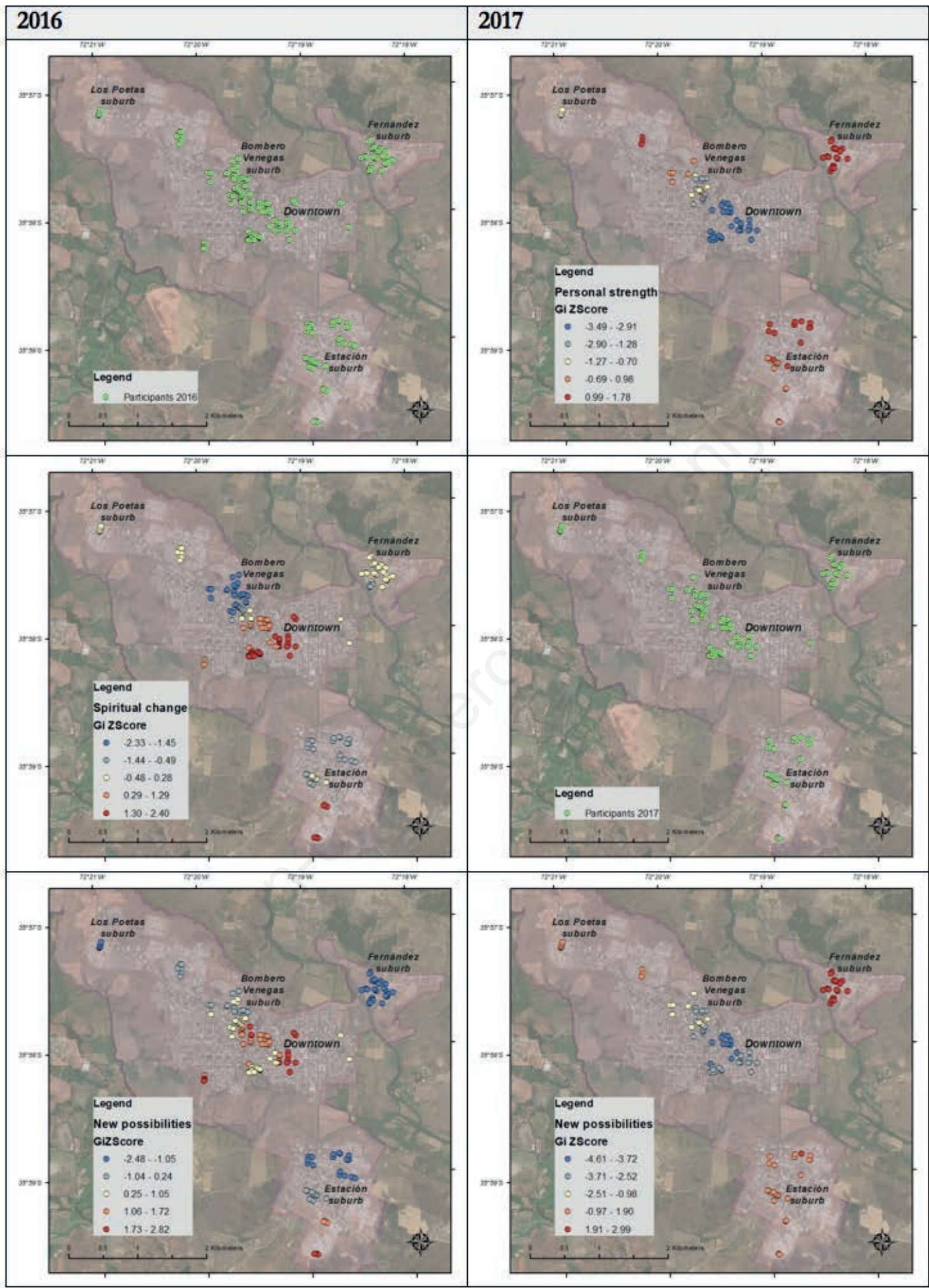

Figure 2. Continued from previous page. Continued on the next page. 


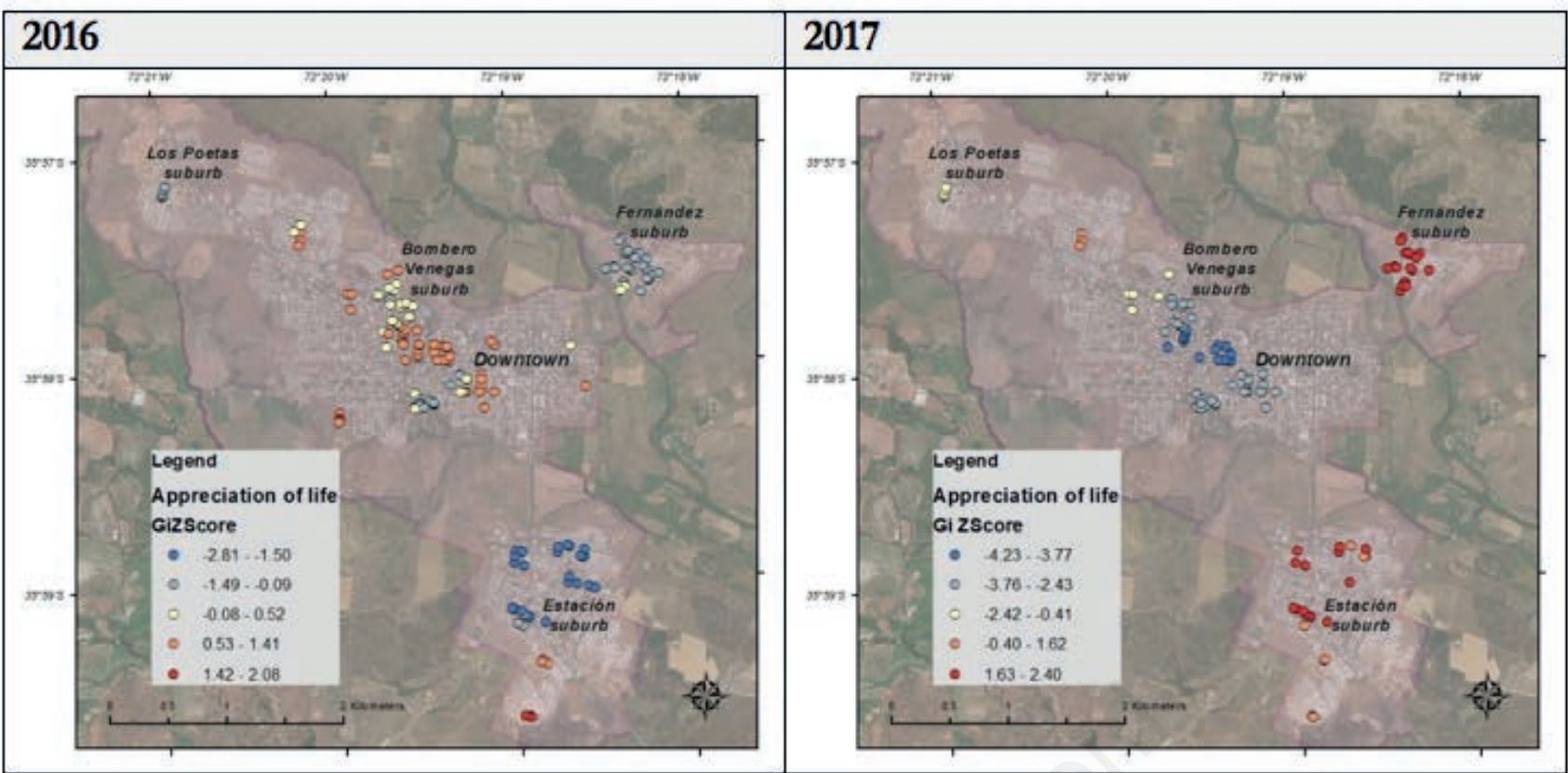

Figure 2. Continued from previous page.

Table 2. Global Moran's I result for analyzed variables in 2016 and 2017.

\begin{tabular}{|c|c|c|c|c|c|c|c|c|}
\hline \multirow[b]{2}{*}{ Variable } & \multicolumn{4}{|c|}{2016} & \multicolumn{4}{|c|}{2017} \\
\hline & Index & Z-score & P-value & Pattern & Index & Z-score & P-value & Pattern \\
\hline PTSD symptoms & 0.1314 & 3.3441 & $0.0008^{*}$ & Clustered & 0.0858 & 1.4461 & 0.1481 & Random \\
\hline PTSD reactions & 0.1698 & 4.2913 & $0.0000^{*}$ & Clustered & 0.1298 & 2.1169 & 0.0343 & Random \\
\hline Suicidal inclination & 0.0274 & 0.8481 & 0.3964 & Random & 0.1487 & 2.4147 & 0.0157 & Random \\
\hline Total PTG & 0.1212 & 3.1211 & $0.0018^{*}$ & Clustered & 0.1604 & 2.5949 & 0.0095 & Random \\
\hline Relating to others & 0.0478 & 1.3189 & 0.1872 & Random & -0.0038 & 0.0870 & $0.9306^{*}$ & Clustered \\
\hline Personal strength & 0.0678 & 1.8076 & 0.0707 & Random & 0.3462 & 5.3935 & $0.0000^{*}$ & Clustered \\
\hline Spiritual change & 0.1050 & 2.7080 & $0.0068^{*}$ & Clustered & 0.0842 & 1.4242 & 0.1544 & Random \\
\hline New possibilities & 0.1797 & 4.5326 & $0.0000^{*}$ & Clustered & 0.2656 & 4.1482 & $0.0000^{*}$ & Clustered \\
\hline Appreciation of life & 0.0856 & 2.2385 & $0.0252^{*}$ & Clustered & 0.2943 & 4.5920 & $0.0000^{*}$ & Clustered \\
\hline Total PTSD & 0.1772 & 4.4712 & $0.0000^{*}$ & Clustered & 0.2224 & 3.5001 & 0.0005 & Random \\
\hline
\end{tabular}

* statistically significant at the $\mathrm{P}<0.05$ level

Table 3. Mean values for variables in 2016 and 2017 at high and low cluster areas.

\begin{tabular}{|c|c|c|c|c|}
\hline \multirow[b]{2}{*}{ Variable } & \multicolumn{2}{|c|}{2016} & \multicolumn{2}{|c|}{2017} \\
\hline & High cluster & Low cluster & High cluster & Low cluster \\
\hline PTSD symptoms & $8.5 \pm 2.6$ & $3.2 \pm 4.2$ & - & - \\
\hline PTSD reactions & $11.5 \pm 5.5$ & $3.6 \pm 6.5$ & - & - \\
\hline Suicidal inclination & - & - & - & - \\
\hline Total PTG & $73.4 \pm 18.6$ & $64.5 \pm 17.0$ & - & - \\
\hline Relating to others & - & - & $31.24 \pm 4.0$ & $26.21 \pm 4.8$ \\
\hline Personal strength & - & - & $17.82 \pm 1.9$ & $15.18 \pm 3.5$ \\
\hline Spiritual change & $8.1 \pm 3.1$ & $6.0 \pm 2.8$ & - & - \\
\hline New possibilities & $15.2 \pm 4.8$ & $11.5 \pm 4.3$ & $21.90 \pm 2.9$ & $18.15 \pm 3.7$ \\
\hline Appreciation of life & $10.5 \pm 3.4$ & $8.7 \pm 3.6$ & $12.97 \pm 1.8$ & $10.20 \pm 3.3$ \\
\hline Total PTSD & $19.7 \pm 7.4$ & $6.7 \pm 10.7$ & - & - \\
\hline
\end{tabular}




\section{Conclusions}

The results confirm that disruptive and healthy responses are linked to the spatial and temporal dimensions after a critical event such as a disaster has occurred, and that there is a change in the geographical distribution of the responses between 6 and 7 years after the event. Previous studies have shown that disruptive responses increase when people are more exposed to the event (Leiva-Bianchi et al., 2017). However, the passage of time implies a decrease in exposure, given the reconstruction of the houses and the social support received. This would allow, for example, an increase in psychological well-being and positive responses in people (such as engagement in interpersonal contacts as well as beliefs about mutual helpfulness and benevolence) (Kaniasty, 2012).

In parallel, healthy responses continue to evolve over time and space. This complements the theory of disruption trajectories. After a disaster, there is a proportion of people (e.g., $30 \%$ in the case of earthquakes) who will present disruptive responses. However, most will respond in a healthy way to the event, either because they recover; that is, they undergo an initial disruption and quickly return to pre-event health levels, or because they always maintain high levels of healthy responses and do not develop symptoms of disruption (Bonanno, 2004). In this regard, these findings complement the theory in two ways:

i) Healthy responses with respect to the way people relate to others and personal mental strength appear where they were not present before, and tend to decrease where there is more exposure to the event (e.g., downtown). This is explained because the most damaged places in a city are directly assisted by agents external to the same community. This could affect growth variables linked to the relation to other people and also to the control that each one has over their own environment.

ii) Responses can change their spatial distribution after 7 years of the event, as is the case of new possibilities and appreciation of life that previously tended to decrease strongly in the most exposed areas, such as the city centre (downtown). This trend could be explained by the fact that after 7 years, most of the most highly damaged sites have been rebuilt. For its part, spiritual change goes from having a greater presence in more exposed places (and less in the most protected places), to losing its spatial distribution after 7 years. This trend could be explained by the religious beliefs that initially play a very important role for the regulation of emotions, but with the passage of time and in face of positive changes in the environment (e.g., reconstruction, absence of earthquakes), these beliefs cease to be strongly relevant and lose their spatial distribution (Bonanno and Diminich, 2013).

It should be noted that the evolution of disruptive and healthy responses could be affected by other disasters that occurred in rural areas near to Cauquenes City. It must be considered that 7 years after the earthquake in the region, the occurrence of forest fires caused considerable damage to people, their property and their economic activity (Diario Oficial de la República de Chile, 2017). This new event could affect the healthy and/or disruptive responses record over time (Bonanno, 2004; Morland et al., 2008; Morgan et al., 2011; Leiva-Bianchi et al., 2017), making it possible to explain, for example, the general increase of PTSD prevalence in the city, as well as its non-spatial clustering in 2017.

\section{References}

Bonanno GA, 2004. Loss, trauma, and human resilience: have we underestimated human capacity to thrive after extremely aversive events? Am Psychol 59:20-8.

Bonanno GA, Papa A, Lalande K, Westphal M, Coifman K, 2004. The Importance of Being Flexible: The Ability to Both Enhance and Suppress Emotional Expression Predicts LongTerm Adjustment. Psychol Sci 15:482-7.

Bonanno GA, Moskowitz JT, Folkman S, 2005. Resilience to Loss in Bereaved Spouses, Bereaved Parents, and Bereaved Gay Men. J Pers Soc Psychol 88: 827-43.

Bonanno GA, Brewin CR, Kaniasty K, Greca AML, 2010. Weighing the costs of disaster consequences, risks, and resilience in individuals, families, and communities. Psychol Sci Public Interest 11:1-49.

Bonanno, GA, Diminich, ED, 2013. Annual Research Review: Positive adjustment to adversity-trajectories of minimalimpact resilience and emergent resilience. J Child Psychol Psychiatry 54:378-401.

Cairo J, Dutta S, Nawaz H, Hashmi S, Kasl S, Bellido E, 2010. The Prevalence of Posttraumatic Stress Disorder Among Adult Earthquake Survivors in Peru. Disaster Med Public 4:39-46. doi:10.1017/S1935789300002408

Chen Y-Y, Huang X-B, Xiao Y, Jiang Y, Shan X-W, et al., 2015. Spatial Analysis of Schistosomiasis in Hubei Province, China: A GIS-Based Analysis of Schistosomiasis from 2009 to 2013. PLoS ONE 10:e0118362.

Cheng C, 2001. Assessing coping flexibility in real-life and laboratory settings: a multimethod approach. J Pers Soc Psychol 80:814-33.

Diario Oficial de la República de Chile, 2010. [Señala como zona afectada por catástrofe derivada del sismo de gran magnitud a las regiones de Valparaíso, Libertador Bernardo O'Higgins, El Maule, del Bío Bío, Araucanía y región metropolitana. Decreto 150.] [Article in Spanish]. Available from: https://www.bcn.cl/leychile/navegar $\mathrm{i}=1011409 \& \mathrm{f}=2010-03-02 \& \mathrm{p}=$

Diario Oficial de la República de Chile, 2017. [Declara como zona afectada por catástrofe derivada de incendios las provincias de Colchagua y Cardenal Caro, de la región de O'Higgins, y las comunas de Vichuquén y Cauquenes, ambas de la región del 
Maule; y dispone las medidas que indica. Decreto 83.] [Article in Spanish]. Available from: https://www.ben.cl/leychile/navegar?idNorma=1099372

Diario Oficial de la República de Chile, 2019. [Declara zona de escasez a la región del Maule. Decreto 102.] Published on the 6th of September, 2019. [Article in Spanish]. Available from: https://www.bcn.cl/leychile/navegar?idNorma=1137766

Getis A, Aldstadt J, 2004. Constructing the spatial weights matrix using a local statistic. Geogr Anal 36:90-104.

Hobfoll SE, Hall B, Canetti-Nisim D, Galea S, Johnson R, Palmieri P, 2007. Refining our Understanding of Traumatic Growth in the Face of Terrorism: Moving from Meaning Cognitions to Doing what is Meaningful. Appl Psychol-Int Rev 56:345-66. doi:10.1111/j.1464-0597.2007.00292.x

INE, 2019a. [Entrega final: Censo 2017. Estimaciones y Proyecciones de la Población de Chile 1992-2050 (Total País).] [Artcile in Spanish]. Available from: https://www. censo2017.cl/

INE, 2019b. [Estimaciones y proyecciones de la población de Chile 2002-2035 a nivel comunal. Documento metodológico.] [AWebsite in Spanish]. Available from: https://www.ine.cl/ docs/default-source/proyecciones-de-poblacion/metodologia/ proyección-base-2017/estimaciones-y-proyecciones-20022035-comunas-metodología.pdf?sfvrsn= 9459d1b0_4

INE, 2020. [Análisis del efecto del COVID-19 sobre el diseño muestral y las estimaciones de la ENE en EFM 2020. Documentos de trabajo.] [Website in Spanish]. Available from: https://www.ine.cl/docs/default-source/ocupacion-y-desocupacion/documentos-de-trabajo/documentos-de-trabajo/análisisdel-efecto-del-covid-19-sobre-el-diseño-muestral-y-las-estimaciones-de-la-ene-en-efm-2020.pdf?sfvrsn=1645cfb0_4

Interagency Standing Committee (IASC), 2007. IASC Guidelines on Mental Health and Psychosocial Support in Emergency Settings. doi:10.1037/e518422011-002

Kaniasty K, 2012. Predicting Social Psychological Well-Being Following Trauma: The Role of Postdisaster Social Support. Psychol Trauma 4:22-33. doi:10.1037/a0021412

Leiva-Bianchi M, Ahumada F, Araneda A, Botella J, 2017. What is the Psychosocial Impact of Disasters? Meta-Analysis. Issues Ment Health Nurs 39:320-7.

Leiva-Bianchi M, Araneda A, 2015. Confirmatory Factor Analysis of the Post-Traumatic Growth Inventory After the Chilean Earthquake. J Loss Trauma 20:297-305. doi:10.1080/ 15325024.2013.873223
Leiva-Bianchi M, Gallardo I, 2013. Validation of the short posttraumatic stress disorder rating interview (SPRINT-E) in a sample of people affected by F-27 Chilean earthquake and tsunami. Anales de Psicología 29:328-34. doi:10.6018/analesps.29.2.130681

Leiva-Bianchi M, Mena C, Ormazábal Y, Serrano C, 2019. Spatial Clustering of people with memories and responses Six Years After an Earthquake in Cauquenes, Chile. Geospat Health 14:275-280.

Mena C, Fuentes E, Ormazábal Y, Palomo I, 2017. Geographic clustering of elderly people with above-norm anthropometric measurements and blood chemistry. Geospat Health 12:523.

MIDEPLAN, 2010. Encuesta Post Terremoto: Principales resultados. Efectos en la calidad de vida de la población afectada por el terremoto/tsunami. Available from: http://observatorio.ministeriodesarrollosocial.gob.cl/layout/doc/001_informe-encuesta-post-terremoto.pdf

Milliken CS, Auchterlonie JL, Hoge CW, 2007. Longitudinal Assessment of Mental Health Problems Among Active and Reserve Component Soldiers Returning from the Iraq War. JAMA 298:2141-8.

Morgan GS, Wisneski DC, Skitka LJ, 2011. The expulsion from Disneyland: the social psychological impact of 9/11. Am Psychol 66:447-454.

Morland LA, Butler LD, Leskin GA, 2008. Resilience and thriving in a Time of Terrorism. In S. Joseph \& P.A. Linley (Eds). Trauma, Recovery and growth: positive psychology perspectives on posttraumatic stress. Wiley \& Sons Inc. pp. 39-61. Available from: https://psycnet.apa.org/record/2008-03151003

Norris F, Hamblen J, Brown L, Schinka J, 2008. Validation of the Short Posttraumatic Stress Disorder Rating Interview (expanded version, Sprint-E) as a measure of post disaster distress and treatment need. Am J Disaster Med 3:201-212.

Ord JK, Getis A, 1995. Local spatial autocorrelation statistics: distributional issues and an application. Geogr Anal 27:286-306. doi:10.1111/j.1538-4632.1995.tb00912.x

Tedeschi RG, Calhoun LG, 1996. The Posttraumatic Growth Inventory: measuring the positive legacy of trauma. J Trauma Stress 9:455-471.

Zhao F, Cheng S, He G, Huang F, Zhang H, et al., 2013. Spacetime clustering characteristics of tuberculosis in China, 20052011. PLoS One 8:e83605. 